\title{
Analysis of Neologisms in Newspapers
}

\author{
Maboleba Kolobe \\ National University of Lesotho, Maseru, Lesotho
}

\begin{abstract}
The paper set out to explore processing of exocentric compound neologisms as used in Southern African newspapers. It identified structures of these constructions and analyzed their interpretation. The rubric question this paper addressed was: What is the relationship between constituents of an exocentric compound neologism, the exocentric compound neologism itself, and the entity the exocentric compound neologism referred to as used in Southern African newspapers? Grounded on pragmatic framework and WordNet Similarity tool, the paper argued that neologisms processing is based on the knowledge of the world, the context in which the words appear and their individual constituents.
\end{abstract}

Keywords: neologism, pragmatic theory, exocentric, Southern African media

\section{Introduction}

Post apartheid era marked change in the history of media in the sister countries of Lesotho and South Africa. Matjama (2007) states that due to apartheid regime, media growth was stagnated in the two countries because only government-related issues were aired. The situation did not only affect content of what should be broadcasted but also the words used to communicate the content had to be well chosen (Reah, 1998). When the two countries experienced democracy, there was improvement in media communication because in media, people try to outdo each other with more and better words to sell their products and these words become absorbed in their everyday use of language (Yule, 2006). Exocentric compound words also feature in media as communication tool. The contribution of these constructions in media has not been of much interest because of their semantic complexity (exocentric: Definition from Answers.com).

Language is a social phenomenon, and as such it mirrors the society which uses it, at the same time, it affects the minds of the members of the society in which it is used. Its users may think that it happens automatically to apply language anywhere because people learn and know it by heart. Stevenson (1994) affirms that applying language within its cultural surrounding is not that simple. He states that even with literal definitions provided by dictionaries, it is not simple to know what those words mean in their cultural surroundings. Therefore, besides literal translations of words, processing of language is attributed to other external factors addressed in this paper.

\section{Methodology}

Data presented here were collected from feature stories excerpted from four quality newspapers published and circulated in Lesotho and South Africa, namely Lesotho Times, Public Eye, Saturday Citizen, and Sunday

Maboleba Kolobe, lecturer, Ph.D., Department of English, National University of Lesotho. 
Independence covering the period 2011-2013. The two countries were considered for this study because firstly, Lesotho is landlocked and completely surrounded by South Africa. Secondly, both countries use English as the business language (www.pressreference.com/ky-Ma/Lesotho.html). Thirdly, Bereng (2000) states that

[t]he economy of Lesotho is closely tied to that of South Africa for trade, finance, employment and access to the outside world. While South Africa has, for a long time, depended on the migratory labour arrangements whereby Lesotho provided manpower for the mining industry. (p. 40)

On the basis of this situation, it seems inevitable to consider the two countries for this study. The data analysis for the study was done using a machine assisted method. The study adopted Kim and Baldwin (2005) methodology of analysis using WordNet Similarity to measure semantic relation similarity or relatedness between words.

\section{Findings}

Data revealed exocentric compound neologisms identified in the corpus. Katamba (1993) supports productivity in word-formation that morphological theorising accommodates countless words used in conversation. He states that what is advocated for by morphology is that speakers should understand not only "real” words but also potential words instantiated in use in utterances. The following sections present exocentric compound neologisms that featured in the corpus according to their formations.

\section{Structures of Exocentric Compound Neologisms}

\section{String-Like Compound Neologisms}

The following sentences carry compound-like structures made up from strings of words as shown below. To process their meaning, two things are needed. Firstly, language user needs to consider the position and the role of that construction in the sentence in which it appears. For instances, king-of-the-hill in Example (1) is classified as an adjective because it modifies the noun "Galaxy" in that sentence. Moreover, better-devil-you-know in Example (2) functions as an object of the sentence, therefore it is a noun while resources-for-arms in Example (3) is an adjective modifying a noun "trade". Secondly, the meaning of these neologisms relies on the knowledge of the native speaker of the language as that may likely help to know the constituents of the compound word and that knowledge may help determine the meaning of the compound word as a whole.

Example (1) The reviewer even went as far as to say the G2 can be favourably compared with Samsung's king-of-the-hill Galaxy S4 on many fronts.

Example (2) This has led to some factory workers opting for the better-devil-you-know than the friend you do not know.

Example (3) This would give Saracen a foothold in the resources-for-arms trade that characterised Executive Outcomes' military adventures in Angola and Sierra Leone among other trouble spots in the 1990s.

Fromkin and Rodman (1988) add that new words may be formed by stringing together other words to create compound words. The authors argue that there is no limit on the kinds of combinations that occur in English. On the other hand, Bell $(1991,1995)$ also reveals that media uses strings of words to convey what could have been presented in long sentences because of space constrains. 


\section{Pre-modified Compound Neologisms}

There were instances of word pre-modification. Anderson (1992) and Bauer and Renouf (2001) share the view that compound words may contain units that are either larger or smaller than a word. These researchers found out that instances of prefixes such as un-, dis- denote lack of or reverse of what is conveyed by the other constituent. Even in the case of this study, compound neologisms in Examples (4)-(6), express lack of the characteristic expressed by or in the other constituent.

Example (4) So in a way this is the most un-Coen movie the maverick brothers have produced.

Example (5) It has been a process that has been de-linked from the ordinary citizen.

Example (6) Mthethwa's interest... emerge from portraits of women who reclaim disused bricks.

\section{Processing Compound Neologisms}

\section{Constituent-Based Meanings}

The compound words' meanings below could only be deduced from the analysis of their constituents. That is they were first stripped off their status as compound constituents and treated as separate entities in order to give a suitable meaning to the whole compound word.

Example (7) This is a serious matter because we have to work hard or risk being down-listed as a world heritage site in danger.

The exocentric compound neologism down-listed is analyzed as follows.

C1: down (26 senses) /adverb/ from a higher to a lower level or position

C2: listed (6 senses) /verb/ enumerate

Example (8) ..."resist the temptation of joining the chorus of the cynics, the pessimists and the doomsayers who would have us believe that ours is a lost cause".

Doomsayers is an exocentric compound neologism which is analyzed as follows.

C1: doom (4 senses) /verb/ make certain of failure or destruction of

C2: say(ers) (12 senses) $/$ noun/ the chance to speak

Example (9) He wanted to have visibility but in a sort of "distant uncle" kind of way.

The exocentric compound neologism distant uncle is analyzed as thus.

C1: distant ( 5 senses) /adjective/ remote in manner

C2: uncle (2 senses) / noun/ a source of help and advice and encouragement

Example (10) It was the in-thing then; my friends and I just decided to take part.

In-thing is analyzed as an exocentric compound neologism as follows.

CW: in-thing /noun/ unrecognized neologism

C1: in 97 senses) /adjective/ currently fashionable

C2: thing (12 senses) /noun/ a separate and self-contained entity

\section{Partially-Context Based}

There are compound neologisms that are interpreted in consideration of partial context. Thus, the compound neologisms are interpreted through how they are used in context plus through consideration of at least one constituent. For instance, the compound neologisms up-to and legwork gathered no contribution from any of its constituents but their meanings could be processed in consideration of context. 
Example (11) When I saw him on the day of the abduction, I had no idea he was up-to no good.

The exocentric compound neologism up-to is analyzed in the following manner.

CW: up-to /adjective/ busy or occupied with

C1: up (14 senses) $\sim$ no match sense

C2: to $\sim$ no match sense

Example (12) Ministers and civil servants are no longer armchair officers but engaged in legwork to find, discuss and answer the concerns from the electorate through media presentations and continuous visits to villages for report back, a sign of transparency and accountability.

The exocentric compound neologism legwork is analyzed in the following manner.

CW: legwork /noun/ unrecognized neologism

C1: leg (9 senses) /noun/ no sense match

C2: work (34 senses) /noun/ activity directed toward making or doing something

\section{Totally-Context Based}

The data reveal compound neologisms that are interpreted from the context only. Thus, even if such formations are recognized and interpreted by the analysis tool, together with its constituents, the way it is used in context does not reflect any relation between the compound entity and the compound constituents; therefore, it could only be understood through the context in which it appears. Tailwinds and knee-jerk are such examples.

Example (13) That's despite positive tailwinds such as record-low unemployment, high consumer confidence... government aimed at stimulating vehicle purchases.

CW: tailwinds $/$ noun/ wind blowing in the same direction as the path of a ship or aircraft

C1: tail (11 senses) $/$ verb/ trail

C2: winds (15 senses) $/$ noun/ an indication of potential opportunity

Example (13) They're a knee-jerk response to awkwardness, he suggests.

The exocentric compound neologism knee-jerk is analyzed in the following manner.

CW: knee-jerk /noun/ a reflex extension of the leg resulting from a sharp tap on the patellar tendon

C1: knee (3 senses) /noun/ joint in the human leg

C2: jerk (11 senses) $/$ noun/ an abrupt spasmodic movement

The present study aligns with Yule (2006) that journalists enjoy outdoing each other by means of generating "better" words, nonetheless, people have the ability of understanding these new formations as stated by Aronoff and Fudeman (2005).

\section{Conclusion}

The paper presented exocentric compound neologisms and how their meanings are processed. The data collected demonstrated differing structures of these constructions. Such included string-like compound neologisms as in king-of-the-hill, better-the-devil-you-know; pre-modified type such as un-Coen, de-linked. The data again revealed ways of interpreting these compound neologism structures. That included compound neologisms interpreted from constituents that make up the compound neologism; those that relied on context in which the compound neologism appears partially and those that required total contribution of context for their interpretation. 


\section{References}

Anderson, S. R. (1992). A-morphous morphology. Cambridge: CUP.

Aronoff, M., \& Fudeman, K. (2005). What is morphology? Fundamentals of Linguistics, 1, 49-54.

Bauer, L., \& Renouf, A. (2001). A corpus based study of compounding in English. Journal of English Linguistics, 29(2), 101-123. Bell, A. (1991). The language of new media. Oxford: Blackwell.

Bell, A. (1995). Language and the media. Applied Linguistics and Related Disciplines, 15, 23-41.

Bereng, P. M. (2000). Privatisation of the media in lesotho-Its relevance in issues of national survival and development. The Political Economy of the Media in Southern Africa Seminar, University of Natal, Natal.

Exocentric. (n.d.). [Definition from Answers.com].

Fromkin, V., \& Rodman, R. (1988). An introduction to language (4th ed.). Fort Worth: Holt, Rinehart and Winston, Inc..

Katamba, F. (1993). Morphology. London: Macmillan Press Limited.

Kim, S. N., \& Baldwin, T. (2005). Automatic interpretation of noun compounds using Wordnet Similarity. In Proceedings of the

Second International Joint Conference on Natural Language Processing (IJC NLP-05) (pp. 945-956). Jeju, South Korea.

Matjama, T. (2007). Presentation on the media environment in Lesotho. Transformation resource centre media workshop.

Retrieved from www.trc.org.ls/LDP_website/downloads/MEDIA ENVIRONMENT-Presentation at TRC.pdf

Reah, D. (1998). The language of newspapers. London: Routledge.

Stevenson, R. L. (1994). Global communication in the twenty-first century. New York: Longman.

Yule, G. (2006). The study of language. New York: Cambridge University Press. 